\title{
Marco Aurelio: entre el dominio del mundo y el dominio de sí mismo
}

Ignacio García Peña

Universidad de Salamanca

nachogp@usal.es

A pesar de la diversidad de sus fuentes, parece claro el hecho de que Heráclito constituye la influencia fundamental del pensamiento estoico. Desde Zenón, fundador de la Escuela en la Atenas del año 300 a. C., hasta Marco Aurelio en el Imperio Romano del siglo II d. C., los miembros de la corriente helenística destacaron siempre el carácter fluyente y dinámico de la realidad, famoso gracias a la imagen del río que encontramos en los fragmentos de Heráclito ${ }^{1}$ y que tantas veces repitiera Platón. El propio Marco Aurelio, de carácter marcadamente melancólico, resalta en múltiples pasajes de su obra la inestabilidad y fugacidad de lo real en su conjunto, y en particular de la vida humana.

1 DK 22 B 12: «Aguas distintas fluyen sobre los que entran en los mismos ríos»; 49a: «Entramos y no entramos en los mismos ríos, somos y no somos»; 91: «Es imposible bañarse dos veces en el mismo río». En un sentido muy parecido afirma Marco Aurelio: «Reflexiona repetidamente sobre la rapidez de tránsito y alejamiento de los seres existentes y de los acontecimientos. Porque la sustancia es como un río en incesante fluir, las actividades están cambiando de continuo y las causas sufren innumerables alteraciones». (V, 23). Tomamos la traducción de: Marco Aurelio, 2005. 
Quizá el concepto de lógos, esa ley racional que vertebra la naturaleza, sea la herencia más destacable que los estoicos recibieran del filósofo de Éfeso. El principio rector, activo y artífice, constituye la divinidad inmanente a la propia naturaleza, que convierte en teología a la física estoica. Este dato resulta especialmente relevante, dada la separación establecida por Platón entre lo material y lo inmaterial, ya que hace del estoicismo la primera filosofía panteísta plenamente consciente. Así se expresa Marco Aurelio a propósito de la unidad y divinidad de la naturaleza, también en consonancia con las exhortaciones de Heráclito a buscar y reconocer lo común:

Todas las cosas se hallan entrelazadas entre sí y su común vínculo es sagrado y casi ninguna es extraña a la otra, porque todas están coordinadas y contribuyen al orden del mismo mundo. Que uno es el mundo, compuesto de todas las cosas; uno el dios que se extiende a través de todas ellas, única la sustancia, única la ley, una sola la razón común de todos los seres inteligentes, una también la verdad, porque también una es la perfección de los seres del mismo género y de los seres que participan de la misma razón².

Gracias al lógos, a esa racionalidad inmanente, el universo es un kósmos, un todo ordenado y coherente regido por una ley armónica; sin embargo, de acuerdo con la concepción de Heráclito, lo real dista mucho de ser una conjunción pacífica de elementos discordantes; la guerra, la lucha, el conflicto, el enfrentamiento es precisamente la condición de posibilidad de esta armonía, pues «todo sucede según discordia»${ }^{3}$.

2 Ver Marco Aurelio, Libro VII, meditación 9.

3 DK 22 B 8. 
Guerra y oposición de contrarios constituyen los caracteres esenciales de la realidad, a pesar de no ser siempre evidente, dado que «la naturaleza gusta de ocultarse» ${ }^{4}$. Precisamente, el equilibrio en la tensión entre los opuestos o la sustitución y cambio recíprocos hacen posible el orden y la armonía ${ }^{5}$.

Los estoicos asimilaron esta tesis heraclítea, a pesar de que no la desarrollaron en profundidad, ya que otra de sus influencias en el ámbito de la física fue el hilemorfismo aristotélico, que les permitió identificar el elemento divino con la propia naturaleza, postulando la unión indisoluble entre el principio activo, ese lógos que es fuego artífice, y el pasivo, la materia interpenetrada por esa divinidad ordenadora. En Epicteto, sin duda una de las influencias más importantes en el pensamiento de Marco Aurelio, encontramos muestras de estas asimilaciones por parte de la escuela estoica:

En eso consiste la educación, en aprender a querer cada una de las cosas tal y como son. ¿Cómo son? Como las ordena el que las ordenó. Ordenó que hubiera verano e invierno, fecundidad y esterilidad, virtud y maldad y todas las demás oposiciones de este tipo para armonía del conjunto ${ }^{6}$.

Hay que destacar, no obstante, la otra gran influencia del estoicismo en general y de sus autores romanos en particular. Según cuenta Diógenes Laercio, hay una línea de sucesión que, pasando por Antístenes, Diógenes y Crates, une a Sócrates con Zenón de Citio. Así, el estoicismo parece recoger

$4 \quad$ DK 22 B 123.

5 Especialmente esclarecedoras al respecto resultan las explicaciones de Guthrie, quien señala los distintos sentidos de la identidad de los contrarios en el pensamiento de Heráclito. Véase Guthrie, 1999: 416-420.

6 Ver Epicteto, Libro I, sección XII, párrafo 15 y 16. (Epicteto, 1993). 
elementos de los dos grandes primeros periodos de la filosofía griega: el cosmológico, a través de Heráclito, y el ético y antropológico indirectamente de Sócrates y directamente de los cínicos. Y es ésta una herencia que se resalta muy poco a menudo, siendo, como señalábamos, de especial importancia para el estoicismo romano, teniendo en cuenta su marcado carácter ético.

A pesar de que los estoicos no se caracterizaron por aquella parrhesía o libertad de palabra que hace tan llamativo el comportamiento de Diógenes, las ideas de esfuerzo, resistencia y fortaleza, fundamentales en la escuela cínica, son también esenciales en el estoicismo. Por otra parte, aunque cronológicamente los cínicos son anteriores a las invasiones de Alejandro Magno, suele considerarse que pertenecen al conjunto de escuelas helenísticas, ya que promueven la vida conforme a la naturaleza y consideran que la cultura y la sociedad suponen la principal fuente de corrupción para el individuo. Asimismo, destacan del carácter socrático el autodominio, que consideran vía directa a la virtud y la felicidad.

En ocasiones se afirma que las distintas escuelas helenísticas, o al menos los considerados socráticos menores, desarrollaron y profundizaron en algún aspecto del carácter y del filosofar de Sócrates. Sin duda, Antístenes admiraba por encima de todo la austeridad y la fortaleza del carácter de su maestro 7 , lo que le llevó a considerarlo un nuevo Heracles, un esforzado defensor de sus convicciones. Pero quizá sea

$7 \quad$ Marco Aurelio en Meditaciones, Libro I, meditación 16, describe a su padre con estas palabras: «Y encajaría bien en él lo que se recuerda de Sócrates: que era capaz de abstenerse y disfrutar de aquellos bienes, cuya privación debilita a la mayor parte, mientras que su disfrute les hace abandonarse a ellos. Su vigor físico y su resistencia, y la sobriedad en ambos casos son propiedades de un hombre que tiene un alma equilibrada e invencible, como mostró durante la enfermedad que le llevó a la muerte». 
útil que nos refiramos a Diógenes, que ya en su época era conocido como el «Sócrates enloquecido». Según nos explica Dudley, uno de los mayores especialistas en el cinismo antiguo, el calificativo es totalmente pertinente, pues Diógenes se propuso llevar al extremo y la exageración aquellos caracteres socráticos, del mismo modo que los directores de un coro dan la nota más alta para que los demás emitieran el tono adecuado ${ }^{8}$. Así, la ironía socrática se convierte en parrhesía, su frugalidad en ascetismo, y su sophrosyne en apatheía (Dudley, 1967:27), es decir, su moderación se torna insensibilidad. En casi todas las corrientes helenísticas encontramos una búsqueda de la ataraxia, de la serenidad del alma, la ausencia de turbación o preocupación. En el estoicismo, en cambio, y a través del cinismo, no se persigue tan sólo esa carencia de aflicciones, sino un estado de imperturbabilidad que haga imposible la menor conmoción en el sujeto.

Estas coordenadas nos permiten ya adentrarnos en el pensamiento de Marco Aurelio, autor en el que quizá se perciba de manera más clara que en ningún otro autor la conjunción y conciliación del pensamiento de Heráclito con el de Sócrates ${ }^{9}$. Pierre Hadot (2013:147-148), refiriéndose en este caso a Epicteto, considera que sus tres principales influencias son: la dialéctica de los megáricos y Aristóteles, la física «materialista» de Heráclito y la tradición moral socrática, que identifica el bien y el mal con el bien y el mal morales, como después hicieran los estoicos. Tendríamos, de este modo, un completo

8 D.L., VI, 35.

9 En una ocasión Marco Aurelio, en Meditaciones, Libro VI, meditación 47, cita a Heráclito, Pitágoras y Sócrates como ejemplos de venerables filósofos. En otro pasaje (VIII, 3) incluye al más famoso cínico: «Alejandro, César y Pompeyo ¿qué fueron en comparación con Diógenes, Heráclito y Sócrates? Estos vieron cosas, sus causas, sus materias, y sus principios guías eran autosuficientes; pero aquéllos, ¡cuántas cosas ignoraban, de cuántas cosas eran esclavos!». 
retrato de las influencias recibidas por los estoicos en consonancia con las tres partes que distinguían en el conjunto de la filosofía: lógica, física y ética. Por supuesto, en mayor medida que en cualquier otra corriente de pensamiento, estas tres disciplinas se hallan unidas de manera indisoluble, pues el lógos no es sólo la capacidad intelectual humana que permite encadenar razonamientos o establecer un criterio de verdad, además de la facultad que rige y dirige nuestra conducta, sino el elemento esencial de la propia physis, su racionalidad inmanente y rectora de los acontecimientos. La tarea del sabio estoico consiste en descubrir esa ley que rige los acontecimientos y ordena todas las cosas para aceptarla y adecuarse a ella.

De esta manera, Marco Aurelio matiza y detalla aquel fragmento de Heráclito, «no escuchándome a mí, sino al lógos, es sabio convenir que todo es uno» ${ }^{10}$, incluyendo el componente cosmopolita típico del estoicismo y la tendencia política que caracteriza especialmente su periodo romano y supone una diferencia fundamental respecto a otras escuelas helenísticas:

Una sola es la luz del sol, aunque la obstaculicen muros, montes, incontables impedimentos; única es la sustancia común, aunque esté dividida en innumerables cuerpos de cualidades peculiares; una es el alma, aunque esté dividida en infinidad de naturalezas y delimitaciones particulares. Una es el alma inteligente, aunque parezca estar dividida. Las restantes partes mencionadas, como los soplos y los objetos sensibles, carecen de sensibilidad y no tienen relación de parentesco mutuo; sin embargo, también a aquéllas las contiene el poder unificador y el peso que las hace converger. Y la

10 DK 22 B 50. 
inteligencia en particular tiende a lo que es de su mismo género, $\mathrm{y}$ se le une, y esta pasión comunitaria no encuentra impedimentos ${ }^{11}$.

La realidad, como señalara Heráclito, es una cierta unidad dinámica, constituida por medio de elementos contrapuestos. Todo está unido y emparentado en la naturaleza, del mismo modo que lo está el conjunto de seres racionales. Por eso, los estoicos romanos no exhortan al aislamiento del individuo, sino a la cooperación y la búsqueda del bien común, aunque desde una perspectiva más cosmopolita que local ${ }^{12}$; sin embargo, a diferencia de Platón y Aristóteles, quienes explícitamente señalaron que la razón constituía una de las partes o facultades del alma, la antropología estoica introdujo una modificación de notable importancia frente a las antiguas concepciones dualistas. El ser humano se compone de cuerpo y alma, que desde antiguo se entendía como el principio de vida y movimiento y compartido, por lo tanto, con los animales. Además, posee un principio rector, el hegemonikón, que comparte con el resto del universo y lo convierte en un individuo con capacidad racional ${ }^{13}$; sin embargo, las conse-

11 Marco Aurelio, Libro XII, meditación 30.

12 Marco Aurelio, Libro IX, meditación 23: «Al igual que tú mismo eres un miembro complementario del sistema social, así también toda tu actividad sea complemento de la vida social. Por consiguiente, toda actividad tuya que no se relacione, de cerca o de lejos, con el fin común, trastorna la vida y no permite que exista unidad, y es revolucionaria, de igual modo que en el pueblo el que retira su aportación personal a la armonía común».

13 Ramón Bach Pellicer, en la introducción a las Meditaciones (2005: 78), es partidario de esta tripartición, pues los textos parecen apoyarla. Señala, además, el vocabulario empleado por el filósofo estoico; sin embargo, otros autores como Hadot no parecen realizar esta distinción, sino más bien incluir ese principio rector como un elemento particular que pertenecería al alma: «El estoico delimita, pues, un centro de autonomía: el alma por oposición al cuerpo, y el principio director (hegemonikón), por oposición al resto del alma» (2013: 163). Habría, según sus palabras: «Un desdoblamiento del alma -en principio vital, por una parte, y en principio pensante, por otra» (2013: 205). 
cuencias de esta modificación no son tanto antropológicas o epistemológicas cuanto éticas. El lógos humano capacita para el reconocimiento del bien y el mal, es un fragmento de la recta razón que ordena todas las $\operatorname{cosas}^{14}$, siendo así el guía interior de nuestra conducta; $y$, según se ha señalado, el estoicismo sólo reconoce valor a lo específicamente ético, por lo que todo cuanto tenga que ver con cuerpo o alma resulta indiferente, a pesar de que algunos estoicos reconocieran algunos bienes corporales y anímicos, y los situasen en la categoría de lo preferible ${ }^{15}$.

A propósito de estos tres componentes de la naturaleza humana, escribe Marco Aurelio: «Esto es todo lo que soy: un poco de carne, un breve hálito vital, y el guía interior» ${ }^{16}$. El concepto de hegemonikón es uno de los más frecuentes en las Meditaciones. La obra, como se sabe, lleva por título ta eis heautón, por lo que constituye un conjunto de reflexiones para sí mismo, con el propósito de tener siempre presentes los principios que deben guiar su acción. Lo que atañe al cuerpo y a la vida resulta indiferente desde el punto de vista moral, aun cuando tengamos la inclinación de conservarlos y favorecer su crecimiento; sin embargo, como se acaba de mencionar, el $\langle$ yo〉 se identifica con el principio rector, que en otros pasajes se denomina inteligencia o nous. Recordando de nuevo a Sócrates, es habitual la mención del daimon o daimonion, pues el

14 D.L., VIII, 88: «Por eso se presenta como fin el vivir conforme a la naturale$\mathrm{za}$, lo que es decir conforme a la naturaleza propia y la de todas las cosas, sin llevar a cabo nada de lo que suele prohibir la ley común, que es la recta razón, que se halla presente en todo, siendo idéntica a Zeus, que es el gobernante real de la ordenación de todo lo existente».

15 Anthony Long dedica un capítulo a las dificultades de algunos estoicos para conciliar los calificativos de indiferente y preferible. Véase Long, 1994: 186-195.

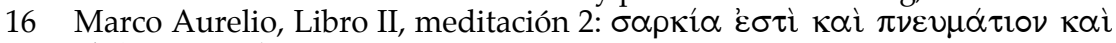

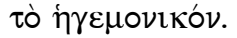


hegemonikón es también la divinidad interior ${ }^{17}$, el fragmento divino en el que, única y exclusivamente, reside la libertad.

Todo está sometido al cambio constante de una realidad bélica y agónica. Existe, no obstante, un resquicio en el que refugiarse de esa lucha y en el que desligarse de ese inexorable curso de acontecimientos establecidos por la Providencia, por la divinidad que vertebra la naturaleza.

Éste es uno de los pasajes más explícitos a propósito de la naturaleza tripartita del ser humano, que posee cuerpo y alma pero que, propiamente, es ese principio rector inteligente. Por eso se percibe también con claridad el contraste entre la necesidad externa y la libertad interna, cuyo reconocimiento debe permitirnos alcanzar la tan ansiada imperturbabilidad:

Tres son las cosas que integran tu composición: cuerpo, hálito vital, inteligencia. De ésas, dos te pertenecen, en la medida en que debes ocuparte de ellas. Y sólo la tercera es propiamente tuya. Caso de que tú apartes de ti mismo, esto es, de tu pensamiento, cuanto otros hacen o dicen, o cuanto tú mismo hiciste o dijiste y cuanto como futuro te turba y cuanto, sin posibilidad de elección, está vinculado al cuerpo que te rodea o a tu hálito connatural, y todo cuanto el torbellino que fluye desde el exterior voltea, de manera que tu fuerza intelectiva, liberada del destino, pura, sin ataduras pueda vivir practicando por sí misma la justicia, aceptando los acontecimientos y profesando la verdad; si tú, repito, separas de este guía interior todo lo que depende de la pasión, lo futuro y lo pasado, $\mathrm{y}$ te haces a ti mismo, como Empédocles «una esfera redonda, ufana de su estable redondez» y te ocupas en vivir exclusivamente

17 Hadot considera que existe equivalencia entre cinco términos empleados por Marco Aurelio: yo, intelecto (nous), el poder de reflexión (dianoia), el principio director (hegemonikon) y el daimon interior (2013: 217). 
lo que vives, a saber, el presente, podrás al menos vivir el resto de tu vida hasta la muerte, sin turbación, benévolo y propicio con tu divinidad interior ${ }^{18}$.

Según hemos podido leer, la realidad es, para Marco Aurelio, un torbellino que fluye, de acuerdo con el pensamiento de Heráclito. No obstante, podemos percibir cierta modificación en la concepción bélica y agónica de la realidad. Según dijimos, para el filósofo de Éfeso hay una contraposición y una guerra constante que, desde una perspectiva general, está equilibrada, sea por la igual fuerza de los elementos en tensión o por la sustitución recíproca de unos en otros. Esto es lo que permite que el universo sea un kósmos, a pesar de que sus enfrentados principios constitutivos no sean evidentes ${ }^{19}$ sino que obliguen al filósofo a indagar en lo profundo.

Podemos afirmar, sin embargo, que Marco Aurelio sustituye esta concepción cosmológica y ontológica de una realidad en guerra y discordia, por otra de carácter físico y político. Este hecho no debe sorprendernos atendiendo a la época histórica en que al emperador le tocó vivir, ya que el siglo II d. C. parece marcar el comienzo de la decadencia de Roma, azotada por constantes invasiones de los pueblos del Norte y Este de Europa. No se trata de una época ni de una guerra de expansión, sino de una defensa frente a una amenaza que se cierne sobre el Imperio; en definitiva, una lucha que el propio Marco Aurelio no inició, sino que se le impuso.

Esta situación sirve precisamente para esclarecer la concepción de lo real de este filósofo estoico. La realidad es lucha,

18 Marco Aurelio, Libro XII, meditación 3.

19 Además del ya mencionado fragmento acerca de la naturaleza como lo oculto, podemos citar aquello otro que reza: «La armonía invisible es mejor que la visible» (DK 22 B 54). 
aunque no encontremos aquí una mención de los contrarios $\mathrm{u}$ opuestos tan habituales en Heráclito y en gran parte de los filósofos presocráticos. Lo real es un torbellino que amenaza al individuo, en consonancia con las ideas de algunas escuelas helenísticas. La filosofía se entiende, así pues, como escudo y protección frente a amenazas exteriores que vienen impuestas.

La lucha entre bárbaros y romanos es tan sólo un ejemplo de la guerra y la contraposición entre lo externo y lo interno. Según dijimos, cuerpo y alma poseen cierto carácter de exterioridad respecto a lo que el individuo verdaderamente es: el hegemonikón o principio rector. Ahí reside la libertad y, por lo tanto, es el lugar en el que refugiarnos y encontrar la calma, la ataraxia.

De los casi veinte años que Marco Aurelio pasó al frente del Imperio, la mayor parte tuvo que dedicarlos a la defensa del limes, de las fronteras que separaban lo interno de lo externo, lo romano de lo bárbaro. Así, su vida política fue como su propuesta filosófica, una búsqueda de refugio interior frente a toda amenaza, de acuerdo con la herencia socrática del estoicismo. El esfuerzo y la constancia que tanto pregonaban los cínicos se hacen imprescindibles pues, como creía Heráclito, la guerra nunca termina sino que es la propia estructura interna de lo real. El conflicto político y filosófico de Marco Aurelio no fue otra cosa que una lucha defensiva, la construcción y defensa de una muralla o una ciudadela que aporten seguridad y tranquilidad.

Según la expresión de Marco Aurelio, que retoma Pierre Hadot como título de su libro sobre el filósofo estoico, la filosofía debe encargarse de construir una ciudadela interior, una muralla que nos proteja frente a cualquier inclemencia. Los propios romanos construyeron largos muros que, junto con las fronteras naturales del Rin y el Danubio, les proporcionaban protección frente a los invasores. 
Esto no parece ser un rasgo exclusivo de Marco Aurelio, ya que, tal como informa Diógenes Laercio, los estoicos utilizaban varias imágenes para referirse a las distintas partes de la filosofía; entre ellas, la comparan «a un huerto frutal: la valla que lo rodea es la lógica, las frutas son la ética, y la tierra y los árboles, la física. $\mathrm{O}$ a una ciudad bien amurallada y administrada de acuerdo con la razón $»^{20}$. Pero, a pesar de lo interesante de esta segunda imagen, la primera nos resulta más útil para comprender lo siguiente. No sólo desde la perspectiva ética la filosofía supone una protección frente a lo externo, sino que la propia lógica estoica muestra cómo una correcta comprensión del conocimiento puede llevarnos a una vida más segura y tranquila.

En este aspecto, como en tantos otros, Marco Aurelio tiene muy presentes las reflexiones de Epicteto. Es bien conocida aquella sentencia según la cual: «no nos preocupamos por las cosas sino por las opiniones que nos formamos de ellas» ${ }^{21}$. A pesar de la aparente simplicidad y obviedad de esta afirmación, detrás de ella se esconde toda una concepción del conocimiento. Según el emperador romano, las cosas no tienen capacidad de afectar al individuo, es decir, al principio rector que se identifica con el 〈yo〉. Evidentemente, nuestro cuerpo nos pone en contacto con las cosas que nos rodean, pero la verdad y el error no dependen de la percepción sino del asentimiento (o disensión) que demos a las representaciones que lleguen al alma. Este poder reside en nuestro intelecto, en el componente divino que forma parte del individuo. Quien considera, por ejemplo, que una guerra es algo temible, se sentirá conmovido, asustado y lleno

20 D.L., VII, 40.

21 Epicteto, Manual, 5. 
de preocupación; sin embargo, si, como el estoico, descubre que las cosas han de ser tal como dispone la divinidad providente, afrontará la situación sin temor, sabiendo que lo exterior es siempre indiferente, precisamente por ser exterior, es decir, por escapar a nuestro poder o control. La pasión, por tanto, no es más que el correlato de un juicio y, si éste está en nuestro poder, también lo está, aunque indirectamente, dicha pasión.

«Las cosas por sí solas no tocan en absoluto el alma ni tienen acceso a ella ni pueden girarla ni moverla. Tan sólo ella se gira y mueve a sí misma, y hace que las cosas sometidas a ella sean semejantes a los juicios que estime dignos de sí» 22 .

Lo único que depende de nosotros son nuestras propias opiniones, nuestros juicios acerca de las cosas, tal como afirmaba Epicteto. El individuo es afectado físicamente por los objetos, e incluso a nivel anímico se genera una imagen involuntariamente. Sin embargo, no hay pasividad en el guía interior ${ }^{23}$, pues constituye el principio activo tanto en el individuo como en la naturaleza, ya que el lógos o fuego siempre es definido como principio activo, frente a la pasividad de la materia que es informada y transformada.

Como se comprueba, las consecuencias de esta doctrina repercuten notablemente en el ámbito ético y en la propuesta estoica de un modo de vida. En primer lugar, nos permiten

22 Marco Aurelio, Libro V, meditación 19.

23 Marco Aurelio, en su Libro VII, meditación 16: «Mi guía interior no se altera por sí mismo; quiero decir, no se asusta ni se aflige [...]. Preocúpese el cuerpo, si puede, de no sufrir nada. Y si sufre, manifiéstelo. También el espíritu animal, que se asusta, que se aflige. Pero lo que, en suma, piensa sobre estas afecciones, no hay ningún temor que sufra, pues su condición no le impulsará a un juicio semejante. El guía interior, por su misma condición, carece de necesidades, a no ser que se las cree, y por eso mismo no tiene tribulaciones ni obstáculos, a no ser que se perturbe y se ponga obstáculos a sí mismo». 
distinguir lo que depende de nosotros y lo que no, lo cual debe llevarnos a suprimir la preocupación acerca de lo que no está en nuestra mano:

Distingue las cosas y ponlas por separado y di: «Lo exterior no depende de mí, el albedrío depende de mí. ¿Dónde buscaré el bien y el mal? En lo interior, en mis cosas s. Pero no califiques nunca las cosas ajenas de «bien〉 ni de «mal〉, ni de «provecho〉 ni de «perjuicio` ni de ningún otro nombre de ese estilo ${ }^{24}$.

En segundo lugar, nos hace conscientes de que la verdadera e importante lucha no es la externa, la que se lleva a cabo con ejércitos y espadas, sino la que tiene lugar en el interior del individuo. Nada externo nos afecta, puesto que las pasiones se generan como consecuencia de nuestros propios juicios. Así pues, de acuerdo con la mencionada tesis según la cual lo que no está en nuestro poder pertenece a la categoría de lo indiferente, el verdadero enemigo de la tranquilidad y la autosuficiencia reside en el interior.

Se buscan retiros en el campo, en la costa y en el monte. Tú también sueles anhelar tales retiros. Pero todo eso es de lo más vulgar, porque puedes, en el momento que te apetezca, retirarte en ti mismo. En ninguna parte un hombre se retira con mayor tranquilidad y más calma que en su propia alma [...] las cosas no alcanzan al alma, sino que se encuentran fuera, desprovistas de temblor, y las turbaciones surgen de la única opinión interior ${ }^{25}$.

24 Epicteto, Libro II, sección V, párrafos 4 y 5.

25 Marco Aurelio, Libro IV, meditación 3. Hadot explica que, a pesar de estar utilizando el concepto de alma, se está refiriendo en este pasaje al guía interior o principio rector (2013: 195). 
De nuevo, nos encontramos ante una doctrina típicamente socrática, que llega al estoicismo a través de los cínicos: la búsqueda del autodominio; sin embargo, el propio término resulta un tanto extraño y contradictorio, tal como advierte Platón:

¿Eso de «ser dueño de sí mismos» no es ridículo? Porque el que es dueño de sí mismo es también esclavo, y el que es esclavo, dueño; ya que en todos estos dichos se habla de una misma persona [...]. Pero lo que me parece -dije- que significa esa expresión es que en el alma del mismo hombre hay algo que es mejor y algo que es peor; y cuando lo que por naturaleza es mejor domina a lo peor, se dice que ‘aquel es dueño de sí mismos, lo cual es una alabanza, pero cuando, por mala crianza o compañía, lo mejor queda en desventaja y resulta dominado por la multitud de lo peor, esto se censura como oprobio, y del que así se halla se dice que está dominado por sí mismo y que es un intemperante ${ }^{26}$.

De manera semejante se expresa Marco Aurelio, señalando que tal incontinencia «consiste en que la parte más divina que se halla en ti, esté sometida e inclinada a la parte menos valiosa y mortal, la de tu cuerpo y sus rudos placeres» ${ }^{27}$.

Quien consigue vencer en la lucha contra sí mismo ${ }^{28}$, es decir, quien no se deja someter por ninguna pasión, se convierte en un hombre virtuoso, sereno e invencible. Así, a pesar de que el estoicismo recalca la incapacidad del ser humano para revertir el orden de los acontecimientos, supo-

26 Platón, República, 431a-b.

27 Marco Aurelio, Libro XI, meditación 19.

28 Podemos recordar aquí las Confesiones de San Agustín, en las que describe apasionadamente el conflicto y la batalla que se libra en su propia alma. En VIII, 8,19 , se refiera a ella como «aquel gran combate de mi morada interior». 
ne al mismo tiempo una exaltación de la libertad, no de acción, sino de pensamiento y decisión. De nuevo empleando un lenguaje bélico ${ }^{29}$, Marco Aurelio describe en este hermoso pasaje la capacidad para encontrar refugio en el propio interior, que nada puede alterar ni afectar:

Ten presente que el guía interior llega a ser inexpugnable, siempre que, concentrado en sí mismo, se conforme absteniéndose de hacer lo que no quiere, aunque se oponga sin razón. ¿Qué, pues, ocurrirá, cuando reflexiva y atentamente formule algún juicio? Por esta razón, la inteligencia libre de pasiones es una ciudadela. Porque el hombre no dispone de ningún reducto más fortificado en el que pueda refugiarse y ser en adelante imposible de expugnar. En consecuencia, el que no se ha dado cuenta de eso es un ignorante; pero quien se ha dado cuenta y no se refugia en ella es un desdichado ${ }^{30}$.

Según hemos señalado, la herencia cínica y socrática lleva a los estoicos, especialmente a los romanos, a una tendencia a la interiorización y a convertir el conflicto y la discordia de Heráclito en una cuestión más moral que metafísica, con el propósito de construir una muralla frente a la amenazante realidad:

29 No queremos dejar sin mencionar dos pasajes en los que el emperador se refiere a la guerra y la lucha como metáfora de la propia vida. «El arte de vivir se asemeja más a la lucha que a la danza en lo que se refiere a estar firmemente dispuesto a hacer frente a los accidentes incluso imprevistos» (Libro VII, meditación 61); «En la práctica de los principios es preciso ser semejante al luchador de pancracio, no al gladiador, porque éste deja la espada de la cual se sirve, y muere, mientras que aquél siempre tiene la mano y no precisa otra cosa sino cerrarla» (Libro XII, meditación 9).

30 Marco Aurelio, Libro VIII, meditación 48. Una idea muy semejante se encuentra ya en Séneca, Epístolas morales a Lucilio, 82: «La filosofía debe erigirse en derredor nuestro, cual muro inexpugnable que la fortuna, aun habiéndole sacudido con muchos artefactos, no puede traspasar. El alma que ha renunciado a los bienes externos se sitúa en un lugar infranqueable y, desde su baluarte, se defiende; debajo de ella todo dardo se abate. No posee la fortuna, como creemos, manos largas; a nadie atrapa, si no está pegado a ella». 
Porque el hombre de estas características que ya no demora el situarse como entre los mejores se convierte en sacerdote y servidor de los dioses, puesto al servicio también de la divinidad que se asienta en su interior, todo lo cual le inmuniza contra los placeres, le hace invulnerable a todo dolor, intocable respecto a todo exceso, insensible a toda maldad, atleta de la más excelsa lucha, lucha que se entabla para no ser abatido por ninguna pasión, impregnado a fondo de justicia, apegado, con toda su alma, a los acontecimientos y a todo lo que se le ha asignado ${ }^{31}$.

\section{Bibliografía}

Dudley, D.R. (1967). A history of cynicism: from Diogenes to the 6th century A.D.: Hildesheim G. Olms.

Epicteto. (1993). Disertaciones por Arriano (trad. de P. Ortiz García). Madrid: Gredos.

Guthrie, W.K.C. (1999). Historia de la filosofía griega. Madrid: Gredos, vol. I.

Hadot, P. (2013). La ciudadela interior. Barcelona: Alpha Decay. Long A. (1994). La filosofía helenística. Madrid: Alianza.

Marco Aurelio. (2005). Meditaciones (trad. de R. Bach Pellicer). Madrid: Gredos.

31 Marco Aurelio, Libro III, meditación 4. 
Resumen

Es conocido que Heráclito constituye la principal influencia del estoicismo, a pesar de lo cual su concepción de la realidad como guerra o lucha de contrarios no fue uno de los aspectos a los que se otorgara mayor relevancia en esta escuela helenística; no obstante, Marco Aurelio, el que probablemente fuese el último gran filósofo estoico de la antigüedad, rescató no sólo la idea heraclítea del flujo universal sino esa concepción bélica de la realidad que conciliada con la herencia socrática del estoicismo conlleva una propuesta de un modo de vida filosófico que nos aporte protección frente a esa realidad turbadora y amenazante. El emperador retoma ideas de carácter moral de otros estoicos romanos como Séneca y Epicteto y, a pesar de no ofrecer profundas especulaciones acerca de la realidad, nos permite comprender la estrecha vinculación entre lógica, física y ética.

Palabras clave: dominio, estoicismo, imperturbabilidad, guerra.

\section{Abstract}

It is well know that Heraclitus, constitutes the main influence of stoicism, despite his conception of the reality as a contrary fight or war was not one of the aspects of higher relevance in the Hellenistic school. However, Marcuse Aurelius, probably was the last great stoic philosopher of the ancient times, not only he rescued the Heracliten idea of universal fluctuation but, also the aggressive conception of reality that, reconcile with the Socratic legacy of stoicism, entails a proposal of a philosophic way of life that provide us protection against a disturbing and threating reality. The emperor takes 
back ideas of moral character from other roman stoics such as Seneca and Epictetus and, despite of not been capable of offering deep speculation about reality, it allow us to understand the narrow link between logic, physics and ethics.

Keywords: command, stoicism, imperturbability, war. 
